\title{
Characteristics and applications of InGaN micro-light emitting diodes on Si substrates
}

Pengfei Tian ${ }^{1}$, Jonathan J. D. McKendry ${ }^{1}$, Zheng Gong ${ }^{1,}$ a) , Shuailong Zhang ${ }^{1}$, Scott Watson ${ }^{2}$, Dandan Zhu ${ }^{3}$, Ian M. Watson ${ }^{1}$, Erdan $\mathrm{Gu}^{1, \text { b) }}$, Anthony E. Kelly ${ }^{2}$, Colin J. Humphreys ${ }^{3}$, and Martin D. Dawson ${ }^{1}$

${ }^{1}$ Institute of Photonics, University of Strathclyde, 106 Rottenrow, Glasgow G4 ONW, United Kingdom

${ }^{2}$ School of Engineering, University of Glasgow, Glasgow, G12 8LT, United Kingdom

${ }^{3}$ Department of Materials Science and Metallurgy, University of Cambridge, Pembroke Street, Cambridge CB2 3QZ, United Kingdom

${ }^{a)}$ Present address: $m L E D$ Ltd., Glasgow G1 1XN, United Kingdom; ${ }^{b)}$ Electronic mail: erdan.gu@ @trath.ac.uk.

Abstract - InGaN micro-light emitting diodes on $\mathrm{Si}$ substrates have been fabricated and characterized. Their abilities for micro-display, high modulation bandwidth of 270 $\mathrm{MHz}$ and data transmission rate of up to $400 \mathrm{Mbit} / \mathrm{s}$ have been demonstrated.

Index Terms - GaN, micro-LEDs, Si, bandwidth.

\section{INTRODUCTION}

GaN-based individually addressable micro-light emitting diode (' $\mu$ LEDs') are a novel format of LED that offers spatially-controllable micro-scale light output patterns with individual emitters of sizes $\leq 100 \mu \mathrm{m}$. These devices have some advantages over larger conventional LEDs, such as high modulation bandwidths [1], reduced device selfheating [2], and higher optical output power densities [3], and have been demonstrated for applications as diverse as visible-light communication (VLC) [1], [4], [5], microdisplays [6], opto-electronic trapping of cells [7] and maskfree photolithography [8].

Growth of InGaN LED material on Si substrates has the potential to substantially reduce the cost of device fabrication [9], [10], including the cost of $\mu$ LED fabrication. However, until now there have not been any reports of $\mu$ LED devices fabricated on Si substrates. Here we report a $10 \times 10$ array of individually-addressable $45 \mu \mathrm{m}$ diameter $\mu$ LEDs, fabricated from a 6" $\mathrm{Si}$ substrate (termed "Si/ $\mu \mathrm{LEDs").}$ These devices are characterized and we show that the $\mathrm{Si} / \mu \mathrm{LEDs}$ can sustain high current densities (up to 6.6 $\mathrm{kA} / \mathrm{cm}^{2}$ ) and has a high electrical-to-optical modulation bandwidth of up to $270 \mathrm{MHz}$. These properties make them ideal device candidates for the applications listed previously, and offer a potentially lower cost route to fabrication of $\mu$ LEDs compared to the previously reported $\mu$ LEDs devices grown on sapphire substrates thus far.

\section{EXPERIMENT}

The Si/ $\mu$ LEDs were fabricated from InGaN LED wafers grown on 6" substrates by metal-organic vapour phase epitaxy (MOVPE). The detailed LED/Si epitaxial structure and $\mu$ LED fabrication process used have been reported previously [1], [11]. Also, $250 \mu \mathrm{m} \times 250 \mu \mathrm{m}$ broad-area LEDs on Si have been fabricated for comparison. Fig. 1(a) shows a completed $10 \times 10 \mu \mathrm{LED} / \mathrm{Si}$ array with each individually-addressable pixel having a diameter of $45 \mu \mathrm{m}$ on a $100 \mu \mathrm{m}$ pitch and the inset demonstrates the uniform light emission from a representative $\mu$ LED pixel. The peak emission wavelength of the $\mu \mathrm{LED} / \mathrm{Si}$ array is $\sim 470 \mathrm{~nm}$.

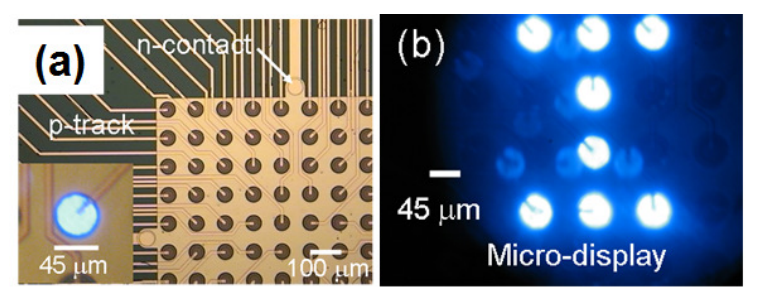

Fig 1. (a) Micrograph of the individually addressable $10 \times 10 \mu$ LEDs array (inset: light emission through the spreading layer of a representative pixel). (b) Light emission of a micro-display pattern.

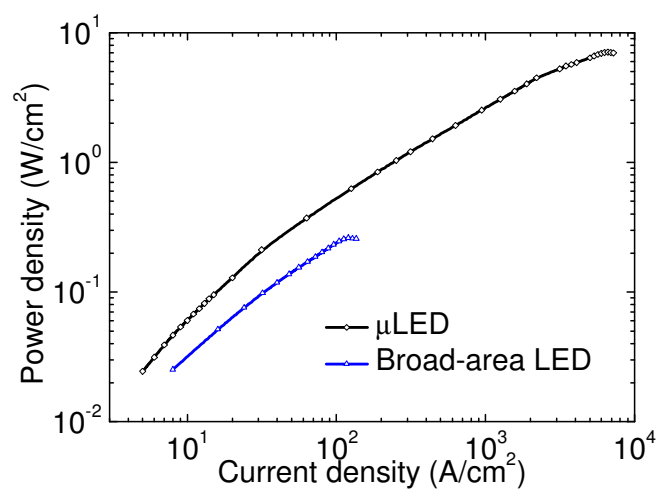

Fig 2. Comparison of power density versus current density characteristics of $\mu$ LED and broad-area LED.

\section{RESULTS AND DISCUSSION}

As shown in Fig 2, compared with $250 \mu \mathrm{m} \times 250 \mu \mathrm{m}$ broad-area LEDs on $\mathrm{Si}$, our measurements show these $\mu$ LEDs have higher optical output power density and can sustain a much higher current density, up to $6.6 \mathrm{kA} / \mathrm{cm} 2$, before thermal rollover. Additionally, good pixel-to-pixel uniformity of these $\mu \mathrm{LED} / \mathrm{Si}$ arrays demonstrates their potential for micro-display applications. As such, Fig. 1(b) shows a light pattern generated by a $\mu \mathrm{LED} / \mathrm{Si}$ array through individually controlling each $\mu$ LED pixel.

We have previously reported that the $\mu$ LEDs on sapphire substrates exhibit higher electrical-to-optical (E-O) modulation bandwidths than their broad-area counterparts [1]. For VLC, the modulation behaviour of the $\mu \mathrm{LED} / \mathrm{Si}$ device was characterised. The E-O modulation bandwidth of a representative $\mathrm{Si} / \mu \mathrm{LED}$ pixel was measured from $0.1 \mathrm{~mA}$ to $110 \mathrm{~mA}$. As shown in Fig. 3(a), an optical modulation bandwidth of $270 \mathrm{MHz}$ has been achieved. The E-O bandwidth shows a strong dependence on the injected current. At present, we attribute this behavior to a complex interplay between the carrier recombination lifetime and the $\mathrm{RC}$ time constant of the device. We note that it is possible to use measurements of this kind to ascertain the recombination 
coefficients in micro-LEDs [12], and we aim to perform such an analysis on this device in due course. In Fig. 3(b), open eye diagrams at $155 \mathrm{Mbit} / \mathrm{s}, 200 \mathrm{Mbit} / \mathrm{s}$, and $300 \mathrm{Mbit} / \mathrm{s}$ could be obtained at $20 \mathrm{~mA}$, however, an open eye diagram at $400 \mathrm{Mbit} / \mathrm{s}$ is only obtained at higher currents, e.g. $80 \mathrm{~mA}$, illustrating the potential for optical data transmission using a single $\mathrm{Si} / \mu \mathrm{LED}$.

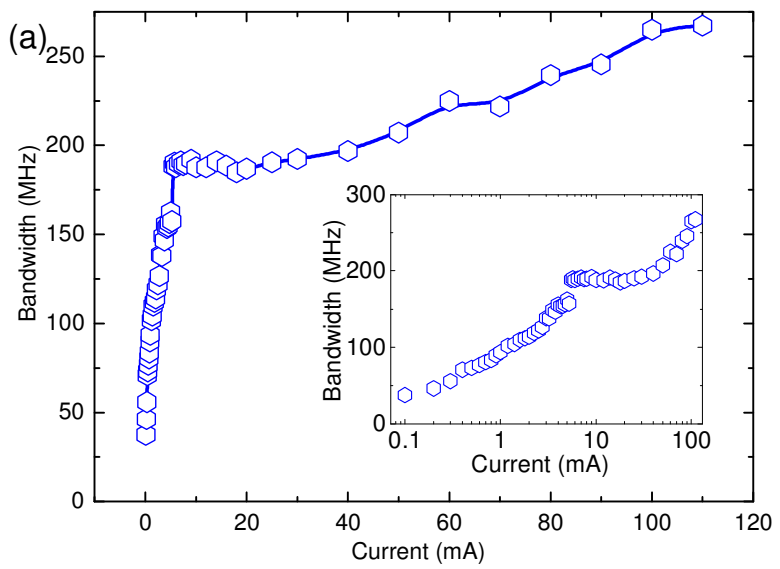

(b)

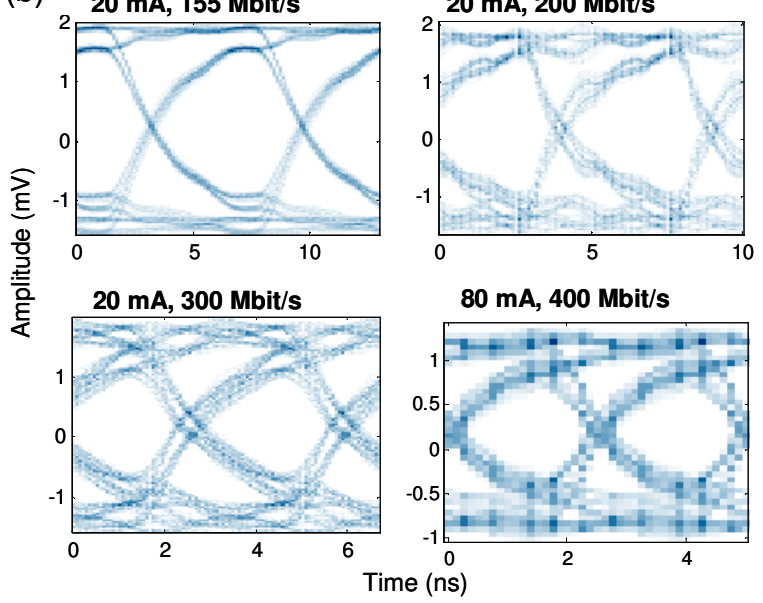

Fig. 3 (a) Bandwidth of one representative $\mu$ LED versus current. Inset: bandwidth versus $\log$ (current). (b) The eye diagrams taken at $155 \mathrm{Mbit} / \mathrm{s}$ (at $20 \mathrm{~mA}$ ), $200 \mathrm{Mbit} / \mathrm{s}$ (at 20mA), $300 \mathrm{Mbit} / \mathrm{s}$ (at 20mA), and $400 \mathrm{Mbit} / \mathrm{s}$ (at $80 \mathrm{~mA})$.

\section{CONCLUSION}

In summary, individually addressable $\mu$ LED arrays have been fabricated for the first time on GaN-on-Si material. This offers a possible way to fabricate $\mu$ LED arrays at a reduced cost compared to using conventional GaN-onSapphire material. The $\mu \mathrm{LED} / \mathrm{Si}$ devices were characterized and shown to be able to generate high-contrast micro-scale light patterns, with higher optical output power densities than their conventional broad-area counterparts. These Si/ $\mu$ LED devices also have electrical-to-optical modulation bandwidths as high as $270 \mathrm{MHz}$, demonstrating the potential these devices have for low cost micro-display and VLC applications.
We acknowledge support from Scottish Universities Physics Alliance, China Scholarship Council, Overseas Research Students Awards Scheme, University of Strathclyde, and grant EP/K00042X/1 from Engineering and Physical Sciences Research Council.

\section{REFERENCES}

J. J. D. McKendry, D. Massoubre, S. Zhang, B. R. Rae, R. P. Green, E. Gu, R. K. Henderson, A. E. Kelly, and M. D. Dawson, "Visible-Light Communications Using a CMOS-Controlled Micro-Light- Emitting-Diode Array," Journal of Lightwave Technology, vol. 30, no. 1, pp. 61-67, Jan. 2012.

Z. Gong, S. Jin, Y. Chen, J. J. D. McKendry, D. Massoubre, I. M. Watson, E. Gu, and M. D. Dawson, "Size-dependent light output, spectral shift, and self-heating of $400 \mathrm{~nm}$ InGaN light-emitting diodes," Journal of Applied Physics, vol. 107, no. 1, p. 013103 , 2010.

H. X. Zhang, D. Massoubre, J. J. D. McKendry, Z. Gong, B. Guilhabert, C. Griffin, E. Gu, P. E. Jessop, J. M. Girkin, and M. D. Dawson, "Indivdually-addressable flip-chip AlInGaN micropixelated light emitting diode arrays with high continuous and nanosecond output power," Optics Express, vol. 16, no. 13, pp. 9918-9926, 2008.

J.-M. Wun, C.-W. Lin, W. Chen, J. K. Sheu, C.-L. Lin, Y.-L. Li, J. E. Bowers, J.-W. Shi, J. Vinogradov, R. Kruglov, and O. Ziemann, "GaN Based Miniaturized Cyan Light Emitting Diodes on Patterned Sapphire Substrate with Improved Fiber Coupling for Very-High-Speed Plastic Optical Fiber Communication," IEEE Photonics Journal, vol. 4, no. 5, pp. 1520-1529, 2012.

P. P. Maaskant, H. Shams, M. Akhter, W. Henry, M. J. Kappers, D. Zhu, C. J. Humphreys, and B. Corbett, "High-Speed Substrate-Emitting Micro-Light-Emitting Diodes for Applications Requiring High Radiance," Applied Physics Express, vol. 6, no. 2, p. 022102, Jan. 2013.

H. X. Jiang, S. X. Jin, J. Li, J. Shakya, and J. Y. Lin, "III-nitride blue microdisplays," Applied Physics Letters, vol. 78, no. 9, p. 1303, 2001.

A. Zarowna-Dabrowska, S. L. Neale, J. J. D. McKendry, D. Massoubre, B. R. Rae, R. K. Henderson, M. J. Rose, H. Yin, J. M. Cooper, E. Gu, and M. D. Dawson, "Miniaturized optoelectronic tweezers controlled by GaN micro-pixel light emitting diode arrays," Optics Express, vol. 19, no. 3, pp. 1714-1720, 2011. B. Guilhabert, D. Massoubre, E. Richardson, J. J. D. McKendry, G. Valentine, R. K. Henderson, I. M. Watson, E. Gu, and M. D. Dawson, "Sub-Micron Lithography Using InGaN Micro-LEDs: Mask-Free Fabrication of LED Arrays," IEEE Photonics Technology Letters, vol. 24, no. 24, pp. 2221-2224, 2012.

D. Zhu, C. McAleese, K. K. McLaughlin, M. Häberlen, C. O. Salcianu, E. J. Thrush, M. J. Kappers, W. a. Phillips, P. Lane, D. J. Wallis, T. Martin, M. Astles, S. Thomas, A. Pakes, M. Heuken, and C. J. Humphreys, "GaN-based LEDs grown on 6-inch diameter Si (111) substrates by MOVPE," in Proceedings of SPIE, 2009, vol. 7231, no. 111, p. 723118.

[10] D. Zhu, C. McAleese, M. Häberlen, C. Salcianu, T. Thrush, M. Kappers, A. Phillips, P. Lane, M. Kane, D. Wallis, T. Martin, M. Astles, N. Hylton, P. Dawson, and C. Humphreys, "Efficiency measurement of GaN-based quantum well and light-emitting diode structures grown on silicon substrates," Journal of Applied Physics, vol. 109, no. 1, p. 014502, 2011.

[11] P. Tian, J. J. D. McKendry, Z. Gong, B. Guilhabert, and I. M. Watson, "Size-dependent efficiency and efficiency droop of blue InGaN micro-light emitting diodes," Applied Physics Letters, vol. 101, p. 231110, 2012.

[12] R. P. Green, J. J. D. McKendry, D. Massoubre, E. Gu, M. D. Dawson, and A. E. Kelly, "Modulation bandwidth studies of recombination processes in blue and green InGaN quantum well micro-light-emitting diodes," Applied Physics Letters, vol. 102, no. 9 , p. $091103,2013$. 